\title{
Exhaled Hydrogen Sulfide Predicts Airway Inflammation Phenotype in COPD
}

\author{
Jing Zhang PhD, Xinmao Wang MSc, Yahong Chen PhD, and Wanzhen Yao MD
}

\begin{abstract}
BACKGROUND: The role of exhaled $\mathrm{H}_{2} \mathrm{~S}$ as a marker of airway inflammation and its relationship with COPD severity remain to be determined. METHODS: Airway inflammation was classified in 77 COPD subjects based on the presence of inflammatory cells in induced sputum. We investigated the association between disease phenotype and exhaled $\mathrm{H}_{2} \mathrm{~S}$, lung function, and plasma levels of several inflammatory factors, including tumor necrosis factor alpha, interleukin-8, and leukotriene $B_{4}$. RESULTS: In total, $33.77 \%$ of enrolled COPD subjects were diagnosed with eosinophilia. These subjects had a longer disease course, smoked fewer cigarettes, and experienced more frequent exacerbation events before study enrollment. However, they also had worse lung function and larger residual volume, they demonstrated greater changes in $\mathrm{FEV}_{1}$ following bronchodilator inhalation. Although levels of plasma inflammatory factors did not significantly differ between subjects with and without eosinophilia, subjects without eosinophilia had significantly higher levels of exhaled $\mathrm{H}_{2} \mathrm{~S}(9.19 \pm 2.74$ vs $7.24 \pm 1.68$ parts per billion, $P=.01)$. Furthermore, exhaled $\mathrm{H}_{2} \mathrm{~S}$ levels were negatively correlated with induced sputum eosinophils $(r=-0.45, P=.05)$, and positively correlated with inspiratory capacity in COPD subjects $(r=0.51, P=.026)$, but did not correlate significantly with plasma inflammatory factors. A cut-off value of 7.10 parts per billion of exhaled $\mathrm{H}_{2} \mathrm{~S}$ predicted a non-eosinophilic phenotype with $68.6 \%$ sensitivity and $77.9 \%$ specificity. CONCLUSIONS: Exhaled levels of $\mathrm{H}_{2} \mathrm{~S}$ were lower in subjects with eosinophilia. Increased levels of exhaled $\mathrm{H}_{2} \mathrm{~S}$ predicted a non-eosinophilic phenotype in our study population. Key words: chronic obstructive pulmonary disease; airway inflammation phenotype; eosinophilia; hydrogen sulfide. [Respir Care 2015;60(2):251-258. (c) 2015 Daedalus Enterprises]
\end{abstract}

\section{Introduction}

COPD is a preventable but incurable disease characterized by persistent air flow limitation and chronic inflammation of the airways, lung parenchyma, and pulmonary vasculature. ${ }^{1}$ Smoking is a major risk factor for COPD

Drs Jing and Chen and Yao are affiliated with the Department of Respiratory Diseases, Peking University Third Hospital; Mr Wang is affiliated with the Department of Respiratory Diseases, Beijing Tongren Hospital, Beijing, People's Republic of China.

This study was supported by National Natural Science Foundation of China grants 81170012 and 81370141 , Research Special Fund for Public Welfare Industry of Health grant 201002008, and Beijing Key Laboratory of Respiratory and Pulmonary Circulation Disorders grant 2013HXFB05.

The first two authors contributed equally to this work.

The authors have disclosed no conflicts of interest. onset, but additional risk factors may contribute to COPD in smokers and non-smokers, such as indoor/outdoor air pollution, occupational exposures, tuberculosis, lower respiratory tract infections during childhood, chronic asthma, poor socioeconomic status, and poor nutrition, ${ }^{1,2}$ leading to progressive air flow limitation associated with enhanced chronic inflammation of the airways and lungs. ${ }^{1}$ Both airway and systemic inflammation contribute to exacerbations of COPD and to declining lung function. COPD is now recognized as a heterogeneous disease with multiple clinical phenotypes, and, importantly, disease progression and prognosis differ significantly among patients.

Correspondence: Yahong Chen PhD, Department of Respiratory Diseases, Peking University Third Hospital, Beijing 100191, People's Republic of China. E-mail: medscizj@126.com.

DOI: $10.4187 /$ respcare.03519 
Induced sputum analysis is used to assess airway inflammatory diseases. ${ }^{3}$ Previous studies have suggested that the bronchial tissues of COPD subjects contain higher levels of neutrophils compared with healthy controls. ${ }^{4}$ Airway neutrophil counts are significantly associated with COPD severity. Moreover, COPD is often referred to as a neutrophilic pulmonary disease, because neutrophils induce pathophysiological changes by secreting proteases and pro-inflammatory cytokines that cause tissue damage. ${ }^{5,6}$ In healthy non-smokers, the cells present in induced sputum are 60-70\% macrophages, 30-40\% neutrophils, and $<2 \%$ eosinophils. In contrast, the proportion of eosinophils in the sputum of COPD patients can reach 20 $40 \% .^{7,8}$ Despite this, the use of induced sputum markers of airway inflammation as indicators of COPD remains controversial.

Previous studies have suggested that, compared with healthy controls, subjects with stable COPD have significantly increased serum levels of hydrogen sulfide $\left(\mathrm{H}_{2} \mathrm{~S}\right)$. In contrast, patients with exacerbations of COPD have significantly decreased levels of serum $\mathrm{H}_{2} \mathrm{~S}$. Thus, levels of endogenous $\mathrm{H}_{2} \mathrm{~S}$ may represent a potential indicator of COPD severity. ${ }^{9-11}$ However, the relationship between levels of exhaled $\mathrm{H}_{2} \mathrm{~S}$ and airway or systemic inflammation has not yet been determined. Recently, the analysis of signaling molecules present in exhaled air has become a popular technique for noninvasive assessment of airway inflammation. ${ }^{12,13}$ To gain a more complete understanding of the relationship between airway inflammation and COPD, we compared clinical phenotypes, exhaled $\mathrm{H}_{2} \mathrm{~S}$ levels, and systemic inflammation levels among subjects who were grouped according to the type of inflammatory cells present in induced sputum.

\section{Methods}

\section{Study Participants}

Between March 2009 and April 2010, 77 subjects (60 male and 17 female, average age $67.09 \pm 8.29$ y) with COPD were recruited at the Peking University Third Hospital. COPD was diagnosed according to the GOLD 2007 criteria for $\mathrm{COPD}^{4}$ and to the COPD treatment guidelines of the Chinese Medical Association (2007 revision). ${ }^{14} \mathrm{~A}$ positive COPD diagnosis required that the ratio of $\mathrm{FEV}_{1}$ to FVC following bronchodilator inhalation was $<70 \%$; additionally, the post-bronchodilator (salbutamol: $400 \mu \mathrm{g}$ ) $\mathrm{FEV}_{1}$ improvement rate had to be $<12 \%$. Inclusion criteria were: (1) age 40-80 y, with stable or declining symptoms of cough, sputum, dyspnea, and wheezing; (2) no antibiotic or glucocorticoid treatment within the previous 2 weeks, and no upper respiratory tract infection within the previous 4 weeks; and (3) no previous diagnosis of bronchiectasis, tuberculosis, asthma, lung cancer, or other re-

\section{QUICK LOOK}

\section{Current knowledge}

COPD is the fourth leading cause of death in the world and an important cause of chronic disability, representing a major economic and social burden worldwide. Airway inflammation is an important pathologic component and target of pharmacotherapy. To date, monitoring airway inflammation has been difficult.

\section{What this paper contributes to our knowledge}

Plasma inflammatory factors were not significantly different between COPD subjects with and without eosinophilia. Subjects without eosinophilia had significantly higher levels of exhaled hydrogen sulfide $\left(\mathrm{H}_{2} \mathrm{~S}\right)$, which was negatively correlated with induced sputum eosinophils and positively correlated with inspiratory capacity. Exhaled $\mathrm{H}_{2} \mathrm{~S}$ predicted a non-eosinophilic phenotype.

spiratory diseases. Subjects with confirmed ongoing eosinophilic bronchitis were excluded. All subjects underwent a brochodilation reversibility test to rule out chronic asthma in patients with symptoms like child/adolescent onset of asthma; variation of symptoms from day to day, symptoms at night or early morning; allergies, rhinitis, and/or eczema; family history of asthma; or largely reversible air flow limitation. ${ }^{4}$ Patients with COPD that developed from asthma (based on the patient's medical history) were excluded.

Subjects with $>3 \%$ eosinophils in the induced sputum were assigned to the eosinophilia group, ${ }^{3}$ and all other subjects were assigned to the non-eosinophilia group. This study was approved by the ethics committee of Peking University Third Hospital (IRB00006761-2012029), and all participants provided written informed consent.

\section{Health Assessment}

Subjects' clinical characteristics, including age, gender, height, weight, smoking history, and disease history were recorded. Dyspnea was scored according to the Medical Research Council scale questionnaire, ${ }^{15}$ and quality of life was assessed according to a Chinese translation of the St George's Respiratory Questionnaire. ${ }^{16}$

\section{Lung Function Tests}

Pulmonary function was measured using a large spirometer (Elite Series DL, Medgraphics, Saint Paul, Minnesota). Measured parameters included $\mathrm{FVC}, \mathrm{FEV}_{1}, \mathrm{FEV}_{1} / \mathrm{FVC}$, 
and inspiratory capacity. Diffusing capacity of the lung for carbon monoxide and total lung capacity were also assessed using the single-breath method and plethysmography, respectively. Reference values for diffusing capacity and total lung capacity were based on those previously published for a Chinese population. ${ }^{17}$

\section{Sampling and Processing of Induced Sputum}

Airway inflammation was assessed by analysis of induced sputum. Participants rinsed their mouths and gargled with water before sputum collection. Subjects inhaled $200 \mu \mathrm{g}$ of salbutamol aerosol, followed by $4 \%$ aerosolized sodium chloride solution 15 min later; $3-5 \mathrm{~mL}$ of sputum was collected, mixed with 4 volumes of $0.1 \%$ dithiothreitol, and then allowed to oscillate at $37^{\circ} \mathrm{C}$ for $15 \mathrm{~min} .{ }^{18}$ The mixture was homogenized by continuous pipetting and passed through a nylon mesh $(48-\mu \mathrm{m}$ pore size) to remove mucus and debris. The filtrate was weighed, and $10 \mu \mathrm{L}$ was reserved for cell counting using a hemocytometer. The filtrate was then centrifuged for $10 \mathrm{~min}$ at 1,500 $\mathrm{rpm}$, and the supernatant was cryopreserved at $-80^{\circ} \mathrm{C}$. The cell pellet was resuspended in phosphate-buffered saline to a concentration of $1 \times 10^{7}$ cells $/ \mathrm{mL}$. Cells were smeared onto a glass slide and stained with WrightGiemsa. A total of 400 non-squamous cells were counted, and the proportion of neutrophils, macrophages, lymphocytes, and eosinophils were calculated. Specimens with more than $20 \%$ of squamous cells were not used for the study.

\section{Detection of Exhaled Hydrogen Sulfide}

Participants performed a slow vital capacity maneuver into 3-L Tedlar reservoir bags (Dalian Haide Technology, Dalian, People's Republic of China) without holding their breath. The reservoir was sealed at the end of the maneuver and then analyzed for exhaled $\mathrm{H}_{2} \mathrm{~S}$ and $\mathrm{NO}$ using an Interscan 4170-1999b portable hydrogen sulfide gas detector and a 4540-1999b portable nitric oxide gas detector (Interscan Corp, Simi Valley, California), respectively.

Approximately $30 \mathrm{~min}$ before each test, a C-12 type filter was connected to the gas inlet to ensure that the reading was stable before adjusting to zero; after this was confirmed, the C-12 filter was removed. Exhaled air was directed to the sampling ports of the detectors. The range for the detector was $0-1,999$ parts per billion. The lower limit of quantitation was $1 \%$ of the full range; repeated readings fell within $0.5 \%$ of the full range. The sample pump flow was controlled by an adjustable voltage regulator and was set at approximately $1 \mathrm{~L} / \mathrm{min}$. The reproducibility of 3 consecutive measurements of exhaled $\mathrm{H}_{2} \mathrm{~S}$ and NO was high (coefficient of variation of $<15 \%$ ).

\section{Detection of Cytokines in Plasma}

A sample of venous blood $(8 \mathrm{~mL})$ was collected in ethylenediaminetetraacetic acid-containing tubes from fasting subjects. Plasma was collected after centrifugation and was cryopreserved at $-80^{\circ} \mathrm{C}$. Plasma levels of tumor necrosis factor alpha, interleukin-8 (IL-8), and leukotriene $\mathrm{B}_{4}$ were measured using enzyme-linked immunosorbent assay (ELISA) kits according to the manufacturer's instructions. Tumor necrosis factor alpha and IL-8 ELISA kits were purchased from Wuhan Boster Biological Technology (Wuhan, People's Republic of China; items EK0525 and EK0413, respectively), and leukotriene $\mathrm{B}_{4}$ ELISA kit was purchased from R\&D Systems (Minneapolis, Minnesota; item 1R610).

\section{Statistical Analysis}

Data that are not normally distributed are presented as median (interquartile range), and inter-group comparisons were made using the rank-sum test. Normally distributed data are presented as mean $\pm \mathrm{SD}$, and inter-group comparisons were made using an independent samples $t$ test. Correlation analysis was performed using the Spearman test. The cut-off concentration of exhaled hydrogen sulfide was selected to yield the highest possible Youden index score (sensitivity + specificity -1 ). The area under the receiver operating characteristic (ROC) curve for exhaled hydrogen sulfide was calculated. The model was considered acceptable when area under the curve $>0.70$. All statistical analyses were performed using SPSS 13.0 (SPSS, Chicago, Illinois). Statistical significance was defined at $P<.05$.

\section{Results}

\section{Subjects' Characteristics}

Seventy-seven COPD subjects (60 male and 17 female) were enrolled in the study; of these subjects, 71 were smokers and 6 had never been smokers. Induced sputum was sampled, and cells were counted. Based on this analysis, $26(33.77 \%)$ subjects were assigned to the eosinophilia group, and 51 participants were assigned to the noneosinophilia group. Neither age nor BMI significantly differed between the 2 groups (Table 1). Before enrollment in this study, subjects with eosinophilia consumed fewer cigarettes, had a longer disease course, and experienced more frequent exacerbation events requiring hospitalization. The lung function of individuals diagnosed with eosinophilia was also worse, showing a higher residual volume. They also displayed a larger change in $\mathrm{FEV}_{1}$ after bronchodilator inhalation. 
Table 1. Characteristics and Lung Function of COPD Subjects With or Without Eosinophilia

\begin{tabular}{lccc}
\hline \hline & $\begin{array}{c}\text { Eosinophilia } \\
\text { Group } \\
(n=26)\end{array}$ & $\begin{array}{c}\text { Non-Eosinophilia } \\
\text { Group } \\
(n=51)\end{array}$ & $P$ \\
\hline Gender (male/female) & $19 / 7$ & $41 / 10$ & .47 \\
Age (y) & $69.3 \pm 9.7$ & $67.7 \pm 7.5$ & .43 \\
BMI & $25.0 \pm 4.6$ & $23.2 \pm 1.4$ & .09 \\
Cigarette consumption & $34.1 \pm 11.2$ & $51.6 \pm 17.7$ & .02 \\
$\quad$ pack-years) & $23 / 3$ & & \\
Smoker/never-smoker & $7.3 \pm 3.8$ & $4.5 \pm 2.8$ & .007 \\
Disease course before & & & \\
$\quad$ inclusion (y) & $4.0 \pm 1.3$ & $2.8 \pm 1.6$ & .003 \\
Instances of exacerbation & & & \\
$\quad$ before inclusion & $3.1 \pm 1.0$ & $2.7 \pm 1.2$ & .19 \\
MRC scores & $69.8 \pm 17.0$ & $61.5 \pm 22.2$ & .13 \\
SGRQ symptom scores & $66.4 \pm 19.7$ & $56.6 \pm 25.8$ & .12 \\
SGRQ activity scores & $38.3 \pm 28.6$ & $30.6 \pm 19.2$ & .16 \\
SGRQ impact scores & $52.2 \pm 19.7$ & $43.4 \pm 19.0$ & .08 \\
SGRQ total scores & & & \\
& & & \\
\hline BMI = body mass index & & & \\
MRC = Medical Research Council & & & \\
SGRC = St George's Respiratory Questionnaire & & \\
\hline
\end{tabular}

\section{Classification of Induced Sputum Samples}

The total number of cells in induced sputum samples obtained from subjects with eosinophilia (median: $4.57 \times$ $10^{6}$ cells $/ \mathrm{mL}$; range: $2.81-5.63 \times 10^{6}$ cells $/ \mathrm{mL}$ ) did not significantly differ from the number detected in samples from subjects without eosinophilia (median: $4.98 \times 10^{6}$ cells $/ \mathrm{mL}$; range: $2.44-6.02 \times 10^{6}$ cells $/ \mathrm{mL}$ ). Subjects with eosinophilia had elevated relative levels of eosinophils (5.70\%) and macrophages (16.40\%) compared with those without eosinophilia $(1.00 \%$ and $7.10 \%, P<.001$ and $P=.004$, respectively). In contrast, subjects without eosinophilia had higher relative levels of neutrophils $(89.00 \%)$ compared with those with eosinophilia $(70.25 \%)(P<$ .001) (Table 2).

\section{Measurement of Exhaled $\mathrm{H}_{2} \mathrm{~S}$ and Levels of Plasma Inflammatory Mediators}

Subjects without eosinophilia had significantly higher levels of exhaled $\mathrm{H}_{2} \mathrm{~S}(9.19 \pm 2.74$ parts per billion) compared with subjects with eosinophilia $(7.24 \pm 1.68$ parts per billion, $P=.01$ ). However, plasma levels of tumor necrosis factor alpha, IL-8, and leukotriene $\mathrm{B}_{4}$ did not significantly differ between the 2 groups (Fig. 1).

\section{Correlation Analysis of Exhaled $\mathrm{H}_{2} \mathrm{~S}$ With Lung Function and Levels of Inflammatory Factors}

Exhaled $\mathrm{H}_{2} \mathrm{~S}$ levels positively correlated with inspiratory capacity $(\mathrm{r}=0.51, P=.03)$, an indicator of lung
Table 2. Induced Sputum Cell Classification and Lung Function in COPD Subjects With or Without Eosinophilia

\begin{tabular}{|c|c|c|c|}
\hline & $\begin{array}{l}\text { Eosinophilia } \\
\text { Group } \\
(n=26)\end{array}$ & $\begin{array}{c}\text { Non-Eosinophilia } \\
\text { Group } \\
(n=51)\end{array}$ & $P$ \\
\hline Macrophages (\%) & $16.40(9.40-28.50)$ & $7.10(4.00-18.80)$ & .004 \\
\hline Lymphocytes (\%) & $2.55(1.40-3.85)$ & $1.70(0.80-3.00)$ & .02 \\
\hline Neutrophils (\%) & $70.25(48.20-80.00)$ & $89.00(79.00-93.80)$ & $<.001$ \\
\hline Eosinophils (\%) & $5.70(3.18-12.35)$ & $1.00(0-1.90)$ & $<.001$ \\
\hline $\mathrm{FEV}_{1} / \mathrm{FVC}(\%)$ & $48.4 \pm 9.6$ & $50.8 \pm 7.7$ & .27 \\
\hline $\mathrm{FVC} \%(\%)$ & $67.6 \pm 12.6$ & $68.9 \pm 16.0$ & .73 \\
\hline $\mathrm{FEV}_{1} \%(\%)$ & $38.4 \pm 16.2$ & $43.5 \pm 15.7$ & .03 \\
\hline$\Delta \mathrm{FEV}_{1}(\%)$ & $8.7 \pm 2.7$ & $6.2 \pm 2.5$ & .009 \\
\hline TLC\% (\%) & $109.5 \pm 27.2$ & $107.4 \pm 21.5$ & .74 \\
\hline RV\% increase $(\%)$ & $133.1 \pm 47.1$ & $123.6 \pm 38.1$ & .68 \\
\hline $\mathrm{D}_{\mathrm{LCO}} \%(\%)$ & $14.1 \pm 4.3$ & $12.1 \pm 6.4$ & .16 \\
\hline \multicolumn{4}{|c|}{$\begin{array}{l}\text { TLC }=\text { total lung capacity } \\
\text { RV = residual volume } \\
\text { D }\end{array}$} \\
\hline
\end{tabular}

function. Exhaled $\mathrm{H}_{2} \mathrm{~S}$ levels tended to be associated negatively with St George's Respiratory Questionnaire activity scores $(\mathrm{r}=-0.43, P=.05)$. Exhaled $\mathrm{H}_{2} \mathrm{~S}$ levels negatively correlated with the percentage of sputum eosinophils in COPD subjects $(\mathrm{r}=-0.45, P=.05)$ (Fig. 2).

\section{Receiver Operating Characteristic Curves}

ROC curves were used to predict exhaled $\mathrm{H}_{2} \mathrm{~S}$ levels corresponding to the non-eosinophilic phenotype (Fig. 3). The area under the curve for exhaled $\mathrm{H}_{2} \mathrm{~S}$ used to predict the non-eosinophilic phenotype was $0.732(P<.01)$. Using a cut-off value of exhaled $\mathrm{H}_{2} \mathrm{~S}$ of 7.10 parts per billion, a sensitivity of $68.6 \%$, and a specificity of $77.9 \%$ were achieved.

\section{Discussion}

The goals of the present study were to describe the clinical features of eosinophilic airway inflammation in COPD subjects and to investigate the relationship among levels of eosinophils, $\mathrm{H}_{2} \mathrm{~S}$, and systemic inflammation. In this study, subjects with eosinophilia accounted for $33.77 \%$ of all participants. In contrast to COPD subjects without eosinophilia, those with eosinophilia had a longer disease course, lower quality of life scores, worse lung function and health status, and experienced more frequent exacerbation events before enrollment in the study. These subjects also consumed fewer cigarettes and exhibited a better response to bronchodilators. Levels of exhaled $\mathrm{H}_{2} \mathrm{~S}$ were reduced in individuals with eosinophilia and significantly correlated with inspiratory capacity. 

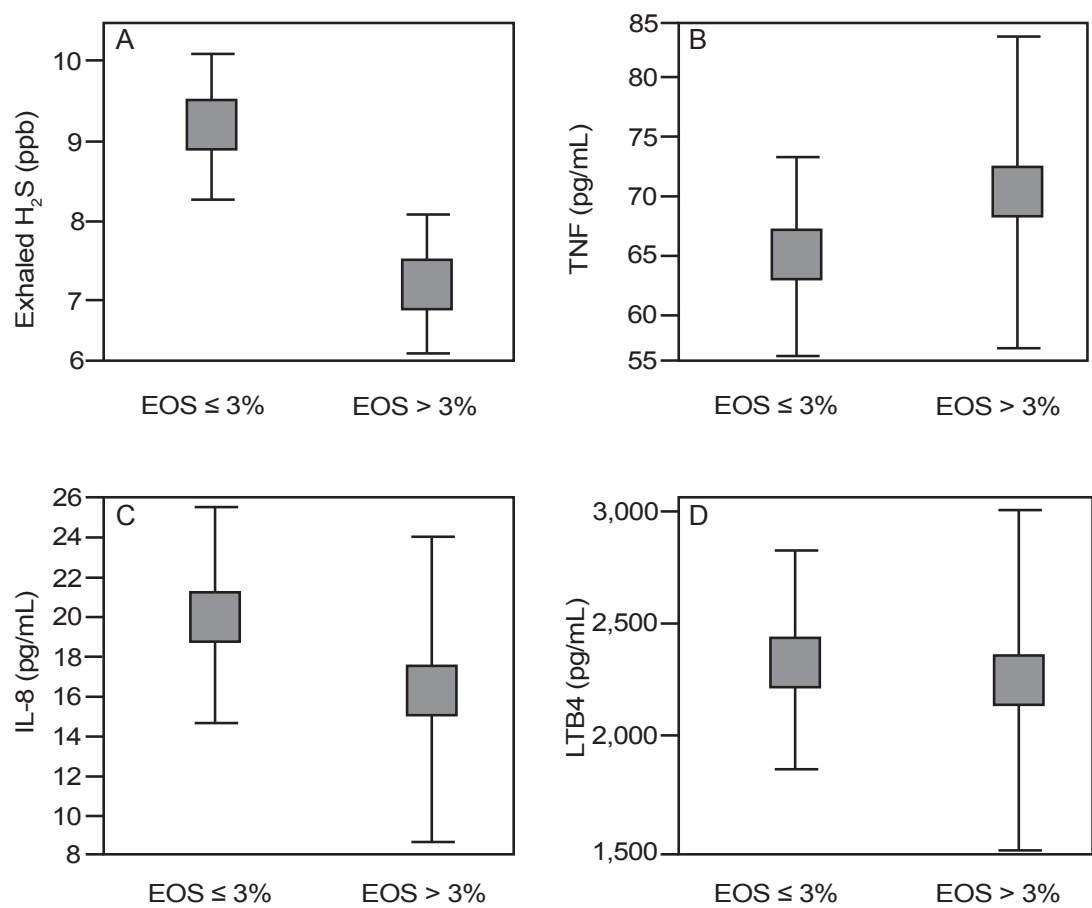

Fig. 1. Exhaled $\mathrm{H}_{2} \mathrm{~S}$ and plasma inflammatory mediators tumor necrosis factor alpha (TNF), interleukin-8 (IL8), and leukotriene $\mathrm{B}_{4}$ (LTB4) in COPD subjects with eosinophila (EOS $>3 \%$ ) or without eosinophila (EOS $\leq 3 \%$ ). A: $P=.01$, B: $P=.51, \mathrm{C}: P=.44$, and D: $P=.82$. Data are shown as mean $\pm \mathrm{SD}$. $\mathrm{ppb}=$ parts per billion.
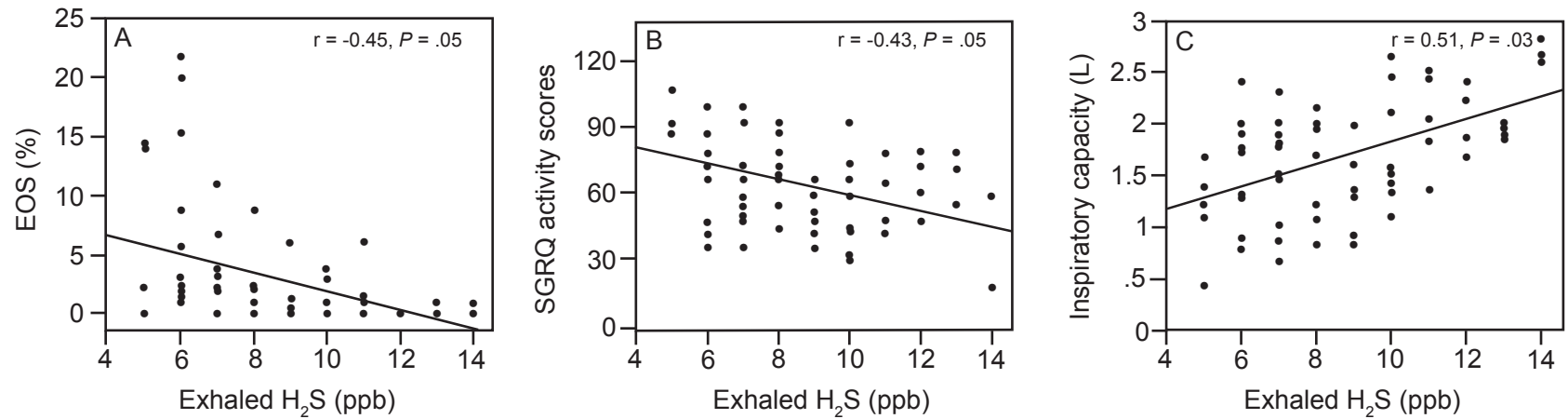

Fig. 2. Correlation analysis of exhaled $\mathrm{H}_{2} \mathrm{~S}$ with eosinophilia (EOS), St George's Respiratory Questionnaire (SGRQ) activity scores, and inspiratory capacity. $\mathrm{ppb}=$ parts per billion.

Previous studies have reported that activated eosinophils negatively correlate with $\mathrm{FEV}_{1}$ in bronchial biopsy specimens. ${ }^{19}$ Moreover, the levels of eosinophils in mucosal bronchial biopsies from patients with acute exacerbations of COPD were 30 -fold greater than the levels in patients with stable COPD. ${ }^{20}$ These findings indicate that eosinophils play a key role, independent of neutrophils, in the development of COPD and exacerbation of airway inflammation. When COPD is complicated by chronic bronchitis, neutrophils can be detected in the airways. ${ }^{21}$ Smoking is thought to induce the neutrophil-associated flow of eosinophils into the airway, but eosinophilic COPD may also develop from eosinophilic bronchitis. Eosinophilic bronchitis is a common cause of chronic, persistent cough in middle-aged adults that is characterized by increased sputum eosinophils; however, these patients do not experience any symptoms of air flow obstruction, airway hyper-responsiveness, or changes in lung function. Although patients exhibit normal lung function at the time of eosinophilic bronchitis diagnosis, they may experience a subsequent dramatic decline in lung function $\left(\mathrm{FEV}_{1}\right)$ coupled with progression to COPD. ${ }^{22}$ Unfortunately, due to the cross-sectional nature of our study, we were unable to determine whether the onset of COPD in study participants was actually due to past events of eosinophilic bronchitis. Additionally, because of the features associated with 


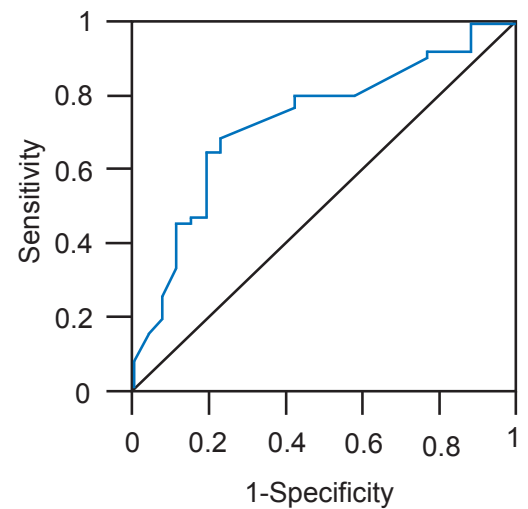

Fig. 3. Receiver operating characteristic (ROC) curve showing the predictive impact of exhaled $\mathrm{H}_{2} \mathrm{~S}$ on non-eosinophilic COPD. The area under the curve was 0.732 , and the cut-off value of exhaled $\mathrm{H}_{2} \mathrm{~S}$ was 7.10 parts per billion with a sensitivity of $68.6 \%$ and a specificity of $77.9 \%$.

eosinophilia (ie, longer disease course and less cigarette smoking), we could not exclusively attribute induced sputum eosinophilia to cigarette smoking. Even though subjects with eosinophilia displayed more severe clinical symptoms and poorer lung function, they exhibited better response to bronchodilators, which is supported by previous findings. ${ }^{20}$ Additionally, subjects with eosinophilia responded well to systemic corticosteroid therapy. ${ }^{23,24}$ Using a noninvasive method, we found that bronchodilator therapy achieved a satisfactory outcome in COPD subjects with induced sputum eosinophilia. However, whether this outcome could be achieved with glucocorticoid therapy requires further study.

$\mathrm{H}_{2} \mathrm{~S}$ functions to regulate the inflammatory response. Levels of $\mathrm{H}_{2} \mathrm{~S}$ in the serum of subjects with stable COPD were significantly higher than those in controls. ${ }^{9,25}$ Importantly, serum $\mathrm{H}_{2} \mathrm{~S}$ levels positively correlate with $\mathrm{FEV}_{1} \%$, induced sputum lymphocyte count, and macrophage count; however, levels negatively correlate with induced sputum neutrophil count. In a smoking-induced chronic COPD rat model, endogenous $\mathrm{H}_{2} \mathrm{~S}$ exerted a protective function, reducing inflammation and bronchodilation. ${ }^{26}$ Intraperitoneal injection of NaHS has been shown to alleviate rat airway hyper-responsiveness, as well as to reduce IL- 8 and tumor necrosis factor alpha levels in rat lung tissues. Another study found that, in a mouse model of COPD, cystathionine $\gamma$-lyase protein levels and the capacity for $\mathrm{H}_{2} \mathrm{~S}$ synthesis in the lungs were significantly reduced. ${ }^{27} \mathrm{We}$ examined the potential relationship between serum and exhaled $\mathrm{H}_{2} \mathrm{~S}$, but no significant correlation was found (data not shown). Serum $\mathrm{H}_{2} \mathrm{~S}$ is distributed in all tissues and organs in levels that are affected by different local and systemic conditions. Only a part of this $\mathrm{H}_{2} \mathrm{~S}$ is exhaled, and the amount being exhaled is dependent upon airway conditions. Compared with serum $\mathrm{H}_{2} \mathrm{~S}$ levels, exhaled $\mathrm{H}_{2} \mathrm{~S}$ appears to reflect changes in the airways. ROC analysis indicated that exhaled $\mathrm{H}_{2} \mathrm{~S}$ could predict the non-eosinophilic phenotype in our study; a cut-off of 7.10 parts per billion of exhaled $\mathrm{H}_{2} \mathrm{~S}$ achieved a sensitivity of $68.6 \%$ and a specificity of $77.9 \%$. Based on our findings, we conclude that levels of exhaled $\mathrm{H}_{2} \mathrm{~S}$ could be used to predict airway inflammation in COPD. Measurement of exhaled $\mathrm{H}_{2} \mathrm{~S}$ is simple and noninvasive. Although analysis of induced sputum is also a noninvasive procedure, it may cause wheezing exacerbation and has a certain failure rate. Furthermore, the induced sputum specimen requires processing before it can be analyzed for cell type and count.

COPD subjects with eosinophilia have lower levels of $\mathrm{H}_{2} \mathrm{~S}$ in exhaled gases; exhaled $\mathrm{H}_{2} \mathrm{~S}$ negatively correlates with eosinophil count in induced sputum but positively correlates with lung function (inspiratory capacity) in COPD patients. We previously found that exhaled $\mathrm{H}_{2} \mathrm{~S}$ levels positively correlate with exhaled $\mathrm{NO}$ in patients with COPD. ${ }^{9,13,25}$ This close relationship between exhaled $\mathrm{NO}$ and $\mathrm{H}_{2} \mathrm{~S}$ highlights the possibility that $\mathrm{H}_{2} \mathrm{~S}$ may be useful as a COPD biomarker. Similar to previous studies, we observed no correlation between exhaled $\mathrm{H}_{2} \mathrm{~S}$ and predicted $\mathrm{FEV}_{1}$. However, exhaled $\mathrm{H}_{2} \mathrm{~S}$ did correlate with inspiratory capacity, another indicator of lung function. Inspiratory capacity is well correlated with maximum oxygen intake and exercise tolerance, and is more sensitive to obstructive airway changes than $\mathrm{FEV}_{1}$ during the stable phase. ${ }^{28,29}$ COPD is a complex disease with multiple clinical manifestations, and patients with comparable air flow limitation $\left(\mathrm{FEV}_{1}\right)$ may present with different phenotypes.

COPD pathogenesis is not merely a result of airway inflammation, it is also significantly influenced by systemic inflammation. ${ }^{1}$ We specifically focused on the inflammatory cytokines and chemokines tumor necrosis factor alpha, IL-8, and leukotriene $\mathrm{B}_{4}$, as these factors have been previously shown to play an important role in the development and severity of COPD. ${ }^{1}$ In many diseased states, levels of inflammatory cytokines are increased. However, the relationship between COPD airway inflammation and systemic inflammation remains undefined. Because COPD is characterized by chronic inflammation of the airways, lung parenchyma, and pulmonary vasculature, it is generally believed that COPD-induced pulmonary inflammation is the source of systemic inflammation. Activated inflammatory cells and secreted inflammatory mediators may enter the systemic circulation and/or pulmonary circulation, and activate inflammatory cells, triggering a generalized inflammatory response. However, Vernooy et $\mathrm{al}^{30}$ performed a well-controlled experiment in which they collected both sputum and blood from the same group of COPD patients. They found that sTNF-R55 expression was increased in sputum but not in blood, and that sTNFR75 expression increased in blood but not in sputum. Importantly, neither measurement reliably correlated with $\mathrm{FEV}_{1} \cdot{ }^{30}$ Thus, the authors suggested that systemic inflam- 
mation is not the result of residual local inflammation. ${ }^{30}$ We found that tumor necrosis factor alpha, IL-8, and leukotriene $\mathrm{B}_{4}$ levels did not differ significantly between subjects with and without eosinophilia, nor did levels significantly correlate with exhaled $\mathrm{H}_{2} \mathrm{~S}$.

However, it is important to keep in mind that we measured only a limited number of cytokines and chemokines, and we cannot rule out the possibility that other aspects of the systemic inflammatory response may be significantly altered between these groups. Additionally, our study sample size was small. Furthermore, the present study was cross-sectional, and we did not enroll controls. Finally, patients with ongoing eosinophilic bronchitis were excluded, but we had no mean to assess undiagnosed past events of eosinophilic bronchitis. Future studies, either cohort or longitudinal studies, with a larger sample size and control subjects will allow us to better characterize the inflammatory state of COPD and its relationship with $\mathrm{H}_{2} \mathrm{~S}$.

\section{Conclusions}

In conclusion, subjects with eosinophilia had a longer disease course, poorer lung function, and worse health status. Despite this, they exhibited a better response to bronchodilators, suggesting that airway inflammation could be a useful indicator for COPD phenotypic analysis. Levels of exhaled $\mathrm{H}_{2} \mathrm{~S}$ were lower in subjects with eosinophilia and showed predictive impact on non-eosinophilic phenotype in our study population. ROC curves showed a good sensitivity and specificity of exhaled $\mathrm{H}_{2} \mathrm{~S}$ in predicting COPD without eosinophilia. Whether endogenous $\mathrm{H}_{2} \mathrm{~S}$ participates in the development or progression of COPD, whether it is important in the diagnosis and monitoring of the disease, and whether it is useful as a guide for COPD treatment require further investigation.

\section{REFERENCES}

1. Vestbo J, Hurd SS, Agusti AG, Jones PW, Vogelmeier C, Anzueto A, et al. Global strategy for the diagnosis, management, and prevention of chronic obstructive pulmonary disease: GOLD executive summary. Am J Respir Crit Care Med 2013;187(4):347-365.

2. Salvi SS, Barnes PJ. Chronic obstructive pulmonary disease in nonsmokers. Lancet 2009:374(9691):733-743.

3. Pizzichini E, Pizzichini MM, Gibson P, Parameswaran K, Gleich GJ, Berman L, et al. Sputum eosinophilia predicts benefit from prednisone in smokers with chronic obstructive bronchitis. Am J Respir Crit Care Med 1998;158(5 Pt 1):1511-1517.

4. Rabe KF, Hurd S, Anzueto A, Barnes PJ, Buist SA, Calverley P, et al. Global strategy for the diagnosis, management, and prevention of chronic obstructive pulmonary disease: GOLD executive summary. Am J Respir Crit Care Med 2007;176(6):532-555.

5. Halpin D. NICE guidance for COPD. Thorax 2004;59(3):181-182.

6. Bhowmik A, Seemungal TA, Sapsford RJ, Wedzicha JA. Relation of sputum inflammatory markers to symptoms and lung function changes in COPD exacerbations. Thorax 2000;55(2):114-120
7. Gorska K, Krenke R, Korczynski P, Kosciuch J, Domagala-Kulawik $\mathrm{J}$, Chazan R. Eosinophilic airway inflammation in chronic obstructive pulmonary disease and asthma. J Physiol Pharmacol 2008;59 (Suppl 6):261-270.

8. Brightling CE, McKenna S, Hargadon B, Birring S, Green R, Siva R, et al. Sputum eosinophilia and the short term response to inhaled mometasone in chronic obstructive pulmonary disease. Thorax 2005; 60(3): 193-198

9. Chen YH, Yao WZ, Geng B, Ding YL, Lu M, Zhao MW, Tang CS. Endogenous hydrogen sulfide in patients with COPD. Chest 2005; 128(5):3205-3211.

10. Toombs CF, Insko MA, Wintner EA, Deckwerth TL, Usansky H, Jamil K, et al. Detection of exhaled hydrogen sulphide gas in healthy human volunteers during intravenous administration of sodium sulphide. Br J Clin Pharmacol 2010;69(6):626-636.

11. Insko MA, Deckwerth TL, Hill P, Toombs CF, Szabo C. Detection of exhaled hydrogen sulphide gas in rats exposed to intravenous sodium sulphide. Br J Pharmacol 2009;157(6):944-951.

12. Chung KF. Hydrogen sulfide as a potential biomarker of asthma. Expert Rev Respir Med 2014;8(1):5-13

13. Chen Y, Wang R. The message in the air: hydrogen sulfide metabolism in chronic respiratory diseases. Respir Physiol Neurobiol 2012; 184(2):130-138.

14. Chinese Medical Association Respiratory Diseases Chronic Obstructive Pulmonary Disease Group. Chronic obstructive pulmonary disease treatment guidelines (2007 revision). J Tuberculosis Respir Dis 2007;30(1):8-17.

15. Mahler DA, Wells CK. Evaluation of clinical methods for rating dyspnea. Chest 1988;93(3):580-586.

16. Jones PW, Quirk FH, Baveystock CM. The St George's Respiratory Questionnaire. Respir Med 1991;85 Suppl B:25-31; discussion 3327.

17. $\mathrm{Mu} \mathrm{K}$, Liu S. [National lung function normal value compilation] Beijing: Beijing Medical University, Peking Union Medical College Union Publishing House, 1990.

18. Beier J, Beeh KM, Kornmann O, Buhl R. Induced sputum methodology: validity and reproducibility of total glutathione measurement in supernatant of healthy and asthmatic individuals. J Lab Clin Med 2004;144(1):38-44.

19. Loppow D, Schleiss MB, Kanniess F, Taube C, Jörres RA, Magnussen H. In patients with chronic bronchitis a four week trial with inhaled steroids does not attenuate airway inflammation. Respir Med 2001;95(2):115-121

20. Saetta M, Di Stefano A, Maestrelli P, Turato G, Ruggieri MP, Roggeri A, et al. Airway eosinophilia in chronic bronchitis during exacerbations. Am J Respir Crit Care Med 1994;150(6 Pt 1):16461652.

21. Snoeck-Stroband JB, Lapperre TS, Gosman MM, Boezen HM, Timens W, ten Hacken NH, et al. Chronic bronchitis sub-phenotype within COPD: inflammation in sputum and biopsies. Eur Respir J 2008;31(1):70-77.

22. Berry MA, Hargadon B, McKenna S, Shaw D, Green RH, Brightling CE, et al. Observational study of the natural history of eosinophilic bronchitis. Clin Exp Allergy 2005;35(5):598-601.

23. Saha S, Brightling CE. Eosinophilic airway inflammation in COPD. Int J Chron Obstruct Pulmon Dis 2006;1(1):39-47.

24. Chanez P, Vignola AM, O'Shaugnessy T, Enander I, Li D, Jeffery PK, Bousquet J. Corticosteroid reversibility in COPD is related to features of asthma. Am J Respir Crit Care Med 1997;155(5):15291534.

25. Sun Y, Wang XM, Chen YH, Zhu RX, Liao CC. Exhaled hydrogen sulfide in patients with chronic obstructive pulmonary disease and its 


\section{EXhaled $\mathrm{H}_{2} \mathrm{~S}$ AND COPD Phenotype}

correlation with exhaled nitric oxide. Chin Med J (Engl) 2013; 126(17):3240-3244.

26. Chen YH, Wang PP, Wang XM, He YJ, Yao WZ, Qi YF, Tang CS. Involvement of endogenous hydrogen sulfide in cigarette smokeinduced changes in airway responsiveness and inflammation of rat lung. Cytokine 2011;53(3):334-341.

27. Han W, Dong Z, Dimitropoulou C, Su Y. Hydrogen sulfide ameliorates tobacco smoke-induced oxidative stress and emphysema in mice. Antioxid Redox Signal 2011;15(8):2121-2134.

28. Shen N, Yao WZ, Liu Z, Wang XH, Hao ZT, Liu XF. [Correlation of the quality of life with the inspiratory capacity in patients with chronic obstructive pulmonary disease]. Zhonghua Jie He He Hu Xi Za Zhi 2010;33(4):261-264.

29. O'Donnell DE, Guenette JA, Maltais F, Webb KA. Decline of resting inspiratory capacity in COPD: the impact on breathing pattern, dyspnea, and ventilatory capacity during exercise. Chest 2012;141(3): 753-762.

30. Vernooy JH, Küçükaycan M, Jacobs JA, Chavannes NH, Buurman WA, Dentener MA, Wouters EF. Local and systemic inflammation in patients with chronic obstructive pulmonary disease: soluble tumor necrosis factor receptors are increased in sputum. Am J Respir Crit Care Med 2002;166(9):1218-1224. 